\title{
Development of Si-O-C Based Ceramic Matrix Composites Produced via Pyrolysis of a Polysiloxane
}

\author{
H. D. Akkaş ${ }^{1}$, M. L. Öveçoğlu ${ }^{2}$, M.Tanoğlu ${ }^{3 *}$ \\ İzmir Institute of Technology, ${ }^{1}$ Materials Science Program, ${ }^{3}$ Department of Mechanical \\ Engineering Gülbahçe Campus, 35437 Urla, İzmir, Turkey \\ ${ }^{2}$ Istanbul Technical University, Department of Metallurgical and Materials Engineering \\ Ayazağa Campus, 34449 Maslak, İstanbul, Turkey
}

Keywords: Ceramic matrix composites, pyrolytic conversion, polysiloxanes, active filler controlled pyrolysis.

\begin{abstract}
Pyrolytic conversion of a preceramic polymer, poly(phenyl)siloxane has been investigated to develop ceramic matrix composites (CMCs) at low temperatures with high dimensional stability. Furthermore, the thermal transformation of the polymer precursor under inert atmosphere was monitored. For this purpose, poly(phenyl)siloxanes were cured at about $200{ }^{\circ} \mathrm{C}$ for 2 hours under air and pyrolysed at various temperatures in the range of $900-1500{ }^{\circ} \mathrm{C}$ for 1 hour under inert argon atmosphere. The products of the pyrolytic conversion were analyzed using X-ray diffraction (XRD), thermal analysis (TG and DTA) and scanning electron microscopy (SEM) coupled with EDX analyzer. It was found that pyrolysis under inert atmosphere up to $1300{ }^{\circ} \mathrm{C}$ led to amorphous silicon oxycarbide $\left(\mathrm{SiO}_{\mathrm{x}} \mathrm{C}_{\mathrm{y}}\right)$ ceramics. Conversions at higher temperatures caused the transformation into the crystalline $\beta$-SiC phases. Moreover, to obtain composite monoliths inert $\mathrm{Al}_{2} \mathrm{O}_{3}$ and active $\mathrm{Ti}$ and $\mathrm{Si}$ particulates were incorporated into the polymer as fillers employing compressive moulding at moderate temperatures. During pyrolysis, cross-linked green compacts of the particulate/polymer system were converted into ceramic body and the microstructural parameters and the effects of the filler type on the microstructure were investigated.
\end{abstract}

\section{Introduction}

There is a great interest for low cost, high temperature $\left(<800{ }^{\circ} \mathrm{C}\right)$, near-net-shape ceramic-matrixcomposites (CMCs). The traditional ceramic processing techniques of CMCs such as hot pressing are high-temperature, high-cost processes, and unsuitable for manufacturing complex and near-netshapes. Ceramic manufacturing from pyrolytic conversion of preceramic polymers has gained growing interest in recent years due to their unique combination of low temperature processing, applicability of versatile plastic shaping technologies and microstructural control capabilities. Si containing polymers such as polycarbosilane and polysiloxane have been used for this purpose, however, bulk ceramic manufacturing is limited due to an inherent density increase and shrinkage during pyrolytic conversion [1,2]. To compensate this effect and to obtain near-net shapes with complex geometry, the concept of active filler controlled polymer pyrolysis process (AFCOP) has been developed recently $[1,3,4]$. In this concept, the reactive filler particles such as $\mathrm{B}, \mathrm{Si}, \mathrm{Ti}, \mathrm{CrSi}_{2}$ incorporated into the polymer reacts with the decomposition products of the polymer such as solid carbon or gaseous $\mathrm{CH}_{4}, \mathrm{C}_{6} \mathrm{H}_{6}$ to form new carbide, nitride or oxide phases. The volumetric expansion from the filler phase reaction may compensate the shrinkage and increase ceramic yield upon pyrolytic decomposition of the polymer. 


\section{Experimental Procedure}

Materials. Commercially available poly(phenyl)siloxane (H62C, Wacker Chemie, GE) was used as preceramic precursor. As inert filler, $\alpha-\mathrm{Al}_{2} \mathrm{O}_{3}$ with particle size in the range of $1-5 \mu \mathrm{m}$ and active fillers, $\mathrm{Si}$ and $\mathrm{Ti}$ with particle mesh size of -635 and -100 , respectively, were used.

Sample preparation. To monitor the thermal transformation of the preceramic polymer, neat H62C was vacuumed for half an hour and then casted in Teflon moulds. The cast samples were cured in an oven at $220^{\circ} \mathrm{C}$ under open-air atmosphere and then pyrolysed in an atmosphere controlled tube furnace under Argon flow at various final temperatures (900, 1100, 1200, 1300, 1400, $\left.1500{ }^{\circ} \mathrm{C}\right)$. A typical heating cycle involved heating up to $550{ }^{\circ} \mathrm{C}$ at $10{ }^{\circ} \mathrm{C} / \mathrm{min}$, held at this temperature for 60 min, then a second ramp to the final temperatures at $10{ }^{\circ} \mathrm{C} / \mathrm{min}$ and held the sample for $60 \mathrm{~min}$ and finally cooling the samples to the room temperature. To prepare ceramic bodies, inert $\alpha-\mathrm{Al}_{2} \mathrm{O}_{3}$ filler (60-70 wt.\%), and active $\mathrm{Ti}(30-50$ wt. \%) and $\mathrm{Si}(60 \mathrm{wt} \%)$ was blended with the H62C, vacuumed for half an hour and casted in metal moulds. The specimens were partially stabilized in an oven at about $150{ }^{\circ} \mathrm{C}$ for 3 hours and then uniaxilly pressed under $15 \mathrm{MPa}$ at $220{ }^{\circ} \mathrm{C}$ for 2 hours using a hot press to complete cross-linking and obtain green monoliths. Pyrolysis of the green bodies was carried out in a tube furnace under argon flow using a multi-step heating schedule up to $1100{ }^{\circ} \mathrm{C}$ final temperature.

Pyrolysis products of both the neat polymer and filler added composite monoliths were identified by X-ray diffraction (XRD) technique using Philips X'Pert Pro diffractometer, with $\mathrm{CuK}_{\alpha}$ radiation. Differential thermal analysis (DTA) and thermogravimetric analysis (TGA) of the green bodies was performed to monitor the associated phase changes and weight losses during the reactions, respectively. Microstructural characterization of the pyrolysed samples was performed on polished specimens using a Philips XL 30SFEG field emission scanning electron microscope (SEM) and attached energy dispersive X-ray (EDX) spectrometer.

\section{Results and Discussion}

The thermal conversion from the organic siloxane network into the inorganic ceramic structure was investigated under inert atmosphere at various temperatures. The XRD patterns of the samples pyrolysed at various temperatures are shown in Fig.1. The patterns up to $1300{ }^{\circ} \mathrm{C}$ are characteristic of $\left(\mathrm{SiO}_{\mathrm{x}} \mathrm{C}_{\mathrm{y}}\right)$ amorphous materials. The broad peaks with low intensities at above $1300{ }^{\circ} \mathrm{C}$ are associated to $\beta-\mathrm{SiC}$.

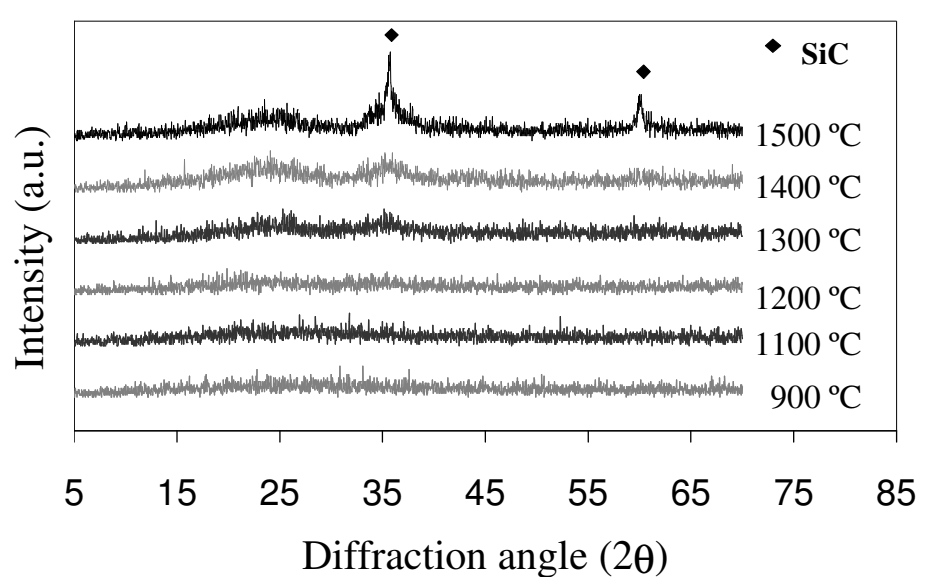

Figure 1. X-ray diffraction patterns of the neat poly(phenyl)dimethylsiloxane pyrolysed at various temperatures. 
As the pyrolysis temperature increases, the peaks become more intense and at about $1500{ }^{\circ} \mathrm{C}$ the characteristic pattern of $\beta-\mathrm{SiC}$ appears with peaks at $2 \theta=36$ and 60 degrees. The $\mathrm{CMC}$ monoliths with inert and active fillers were also synthesised by pyrolsis under Argon. The weight losses of the neat H62C samples were measured as 22.5, 24.7, 26.84, 27.24 and 41.2 wt \% for pyrolysis at 900, $1100,1300,1400,1500{ }^{\circ} \mathrm{C}$, respectively. Also, these values for composite green bodies are; 8.84 , $9.46 \mathrm{wt} \%$ for 70 and $60 \mathrm{wt} \% \mathrm{Al}_{2} \mathrm{O}_{3}$ loaded, 5.96 and 8.54 for 70 and $60 \mathrm{wt} \% \mathrm{SiC}$ loaded samples. These values are related to the polymer amount and the type of the filler used. As expected, the weight losses decrease with lower polymer content and with incorporation of the active fillers. Fig. 2 shows the TGA and DTA analysis results for cured neat polysiloxane and particulate added green bodies. The decomposition of the polymer starts at $500{ }^{\circ} \mathrm{C}$ and significant mass loss occurs at about this temperature. The DTA signal also exhibits an exothermic peak at about $500{ }^{\circ} \mathrm{C}$. During pyrolysis of the polysiloxane between $500-800{ }^{\circ} \mathrm{C}$, an organic-inorganic conversion with release of hydrocarbons such as $\mathrm{CH}_{4}$ and $\mathrm{C}_{6} \mathrm{H}_{6}$ may lead to an amorphous $\mathrm{SiO}_{\mathrm{x}} \mathrm{C}_{\mathrm{y}}$. Above $800{ }^{\circ} \mathrm{C}$, an excess carbon may participate and above $1100{ }^{\circ} \mathrm{C}$ crystalline phases such as $\mathrm{SiO}_{2}$ and $\mathrm{SiC}$ may nucleate.
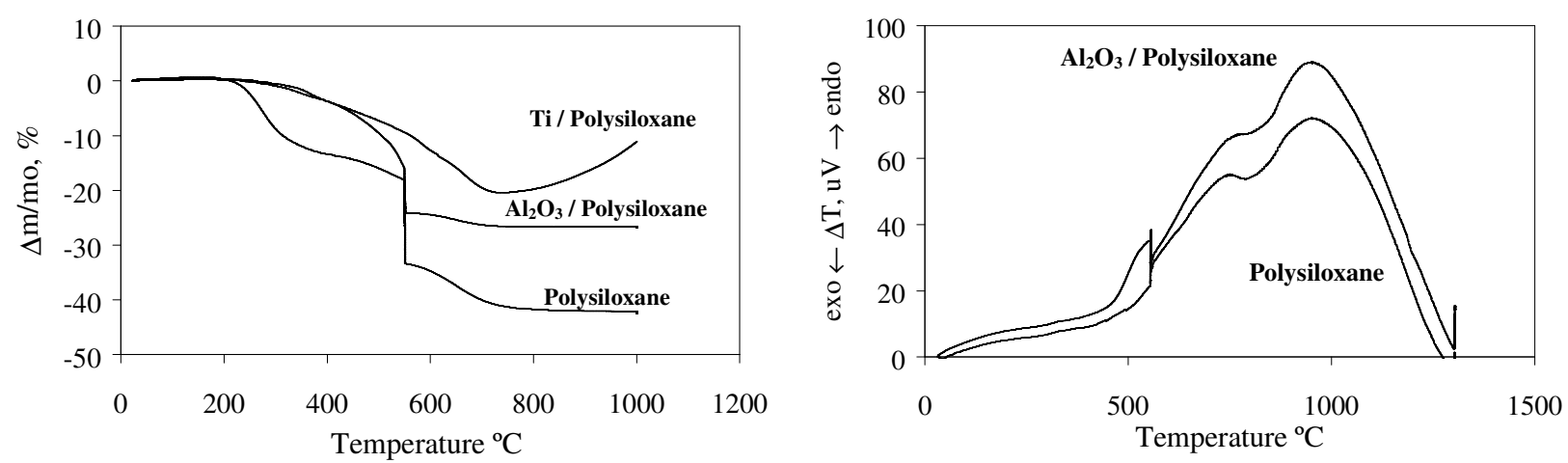

Figure 2. a) TGA curves of neat polymer, $\mathrm{Al}_{2} \mathrm{O}_{3}(50 \mathrm{wt} \%) /$ polymer and $\mathrm{Ti}(50 \mathrm{wt} \%) /$ polymer systems b) DTA curves of neat polymer and $\mathrm{Al}_{2} \mathrm{O}_{3}(50 \mathrm{wt} \%) /$ polymer systems.

In the case of $\mathrm{Al}_{2} \mathrm{O}_{3} / \mathrm{H} 62$ composite system, DTA curves are close to the neat polymer. This indicates that there is no significant effect of the inert $\mathrm{Al}_{2} \mathrm{O}_{3}$ on the pyrolysis process of the polymer. However, for active $\mathrm{Ti}$ or $\mathrm{Si}$ particulate added $\mathrm{H} 62 \mathrm{C}$ system, the weight loss due to thermal degradation of the polymer is progressively compensated above $710{ }^{\circ} \mathrm{C}$ with the increase of weight. The mass increase may be associated with the carborization / oxidation of $\mathrm{Ti}$ and $\mathrm{Si}$ into $\mathrm{TiO}, \mathrm{TiC}$ and $\mathrm{SiO}_{2}$, etc. Furthermore, the XRD pattern of the Ti particulate added polysiloxane samples pyrolyzed at $1100{ }^{\circ} \mathrm{C}$ exhibited characteristic peaks of $\mathrm{TiC}, \mathrm{TiO}$ and $\mathrm{TiSi}$ phases. Fig. 3 shows the fracture surface SEM micrographs of the pyrolysis products of the poly(phenyl)dimethylsiloxane for various temperatures. At lower temperatures, glassy surfaces with low porosity are observed. Higher pyrolysis temperatures yielded uniformly distributed micropores formed due to the density changes from the polymer to the ceramic phases. The SEM-EDX analysis for these samples also confirms the formation of the SiOC structure. Polished surface SEM micrographs for selected inert and active filler added SiOC structures are illustrated in Fig.4. These observations indicate that both type of the filler particulates were uniformly distributed within the SiOC matrices. The visible porosity in composite specimens was less due to the lower content of the polymer in the green compacts.

\section{Summary}

The amorphous SiOC phases were synthesised from the poyrolytic decomposition of a preceramic polymer, poly(phenyl)siloxanes. Moreover, active and inert filler added SiOC-based CMC monoliths were produced. The amorphous SiOC structure was transformed into the crystalline SiC 
phases with uniformly distributed microporous structure at temperatures above $1400 \mathrm{C}$. The mass loss values were affected by the type of the filler and the content of the polymer in green bodies. The results from the active filler incorporated composites indicated the possible compensation of the shrinkage and increase of the ceramic yield above certain conversion temperatures.

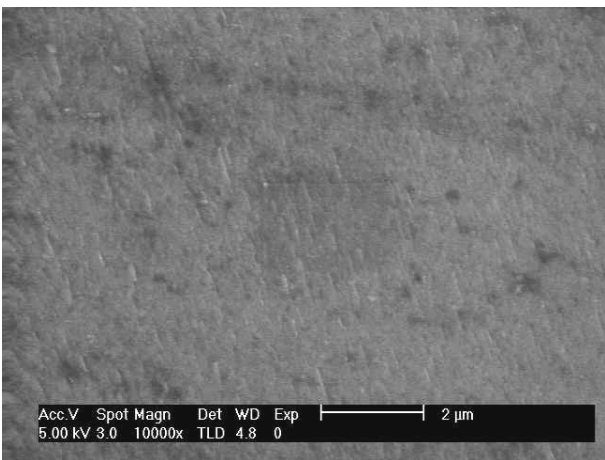

(a)

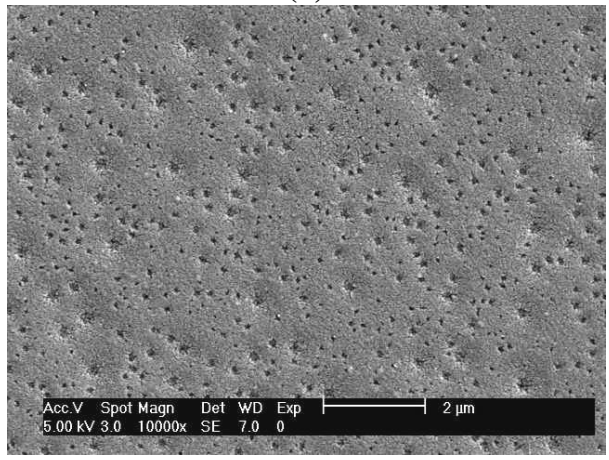

(c)

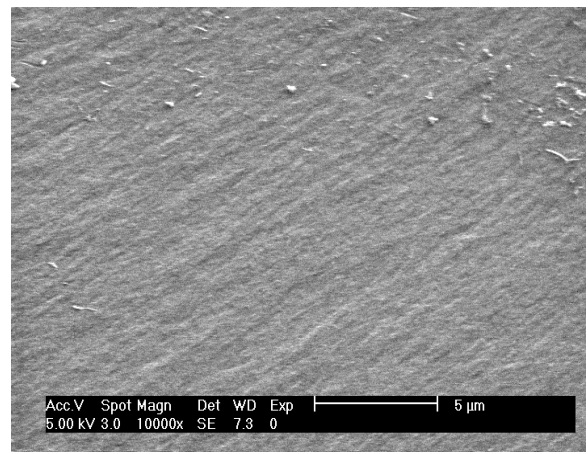

(b)

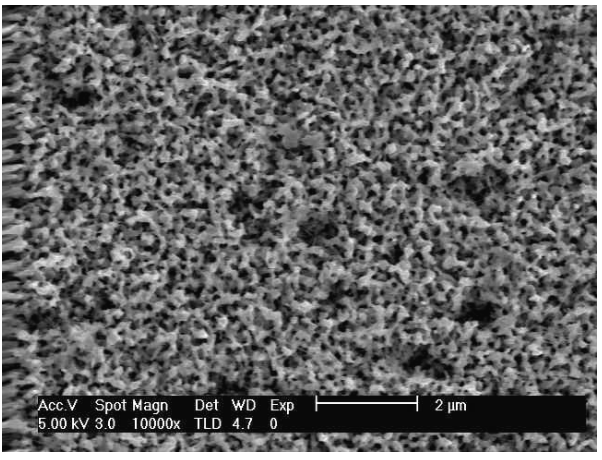

(d)

Figure 3. SEM fracture surface micrographs of the neat poly(phenyl)dimethyl pyrolysed at elevated temperatures : a) 900 b) 1200 , c) 1400 , d) $1500{ }^{\circ} \mathrm{C}$.

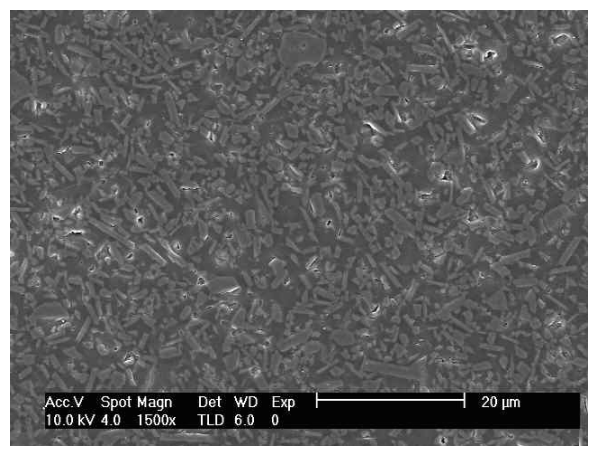

(a)

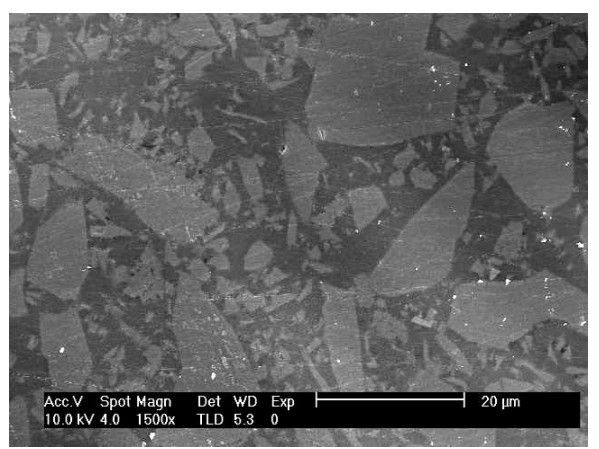

(b)

Figure 4. SEM polished surface micrographs of $60 \mathrm{wt} \%$ a) inert $\mathrm{Al}_{2} \mathrm{O}_{3}$ b) active $\mathrm{Si}$ filled poly(phenyl)dimethylsiloxane pyrolysed at $1100^{\circ} \mathrm{C}$.

\section{Acknowledgements}

The authors gratefully acknowledge the financial support from The Scientific and Technical Research Council of Turkey (TÜBİTAK) for MISAG 215 project.

\section{References}

[1] P. Greil: J. Eu. Ceram. Soc. 18 (1998) 1905.

[2] M. A. Schiavon, E. Radovanovic, I. V. P. Yoshida: Pow. Tech. 123 (2002) 232.

[3] T. Michalet, M. Parlier, F. Beclin, R. Duclos, J. Crampon: J. Eu. Ceram. Soc. 22 (2002) 143.

[4] J. Brus, F. Kolar, V. Machovic, J. Svitilova: J. Non-cryst. Solids. 289 (2001) 62. 


\section{Euro Ceramics VIII}

10.4028/www.scientific.net/KEM.264-268

Development of Si-O-C Based Ceramic Matrix Composites Produced via Pyrolysis of a Polysiloxane 10.4028/www.scientific.net/KEM.264-268.961

\section{DOI References}

[1] P. Greil: J. Eu. Ceram. Soc. 18 (1998) 1905.

10.1016/S0955-2219(98)00129-0

[2] M. A. Schiavon, E. Radovanovic, I. V. P. Yoshida: Pow. Tech. 123 (2002) 232.

10.1016/S0032-5910(01)00461-2 